\title{
Synthesis of Urea by Ammonolysis of Propylene
}

\section{Carbonate}

\author{
Alexander R. Elman ${ }^{1}$, Igor E. Davydov ${ }^{1}$ and Alexander A. Stepanov ${ }^{2}$ \\ 1. Rostkhim, Ltd., 1, Bd. 4, B. Sadovaya, Moscow 123995, Russia \\ 2. Farm-Sintez, Co., 38, Shosse Entuziastov, Moscow 111123, Russia
}

\begin{abstract}
Studying urea formation by ammonolysis of propylene carbonate in a liquid phase showed that this process is two-stage, and proceeds through preferred formation of 2-hydroxypropyl carbamate, besides, the rate of the first stage is much higher than the rate of the second stage (urea formation). With the aid of the HPLC and HPLC/MS methods found some other intermediate products and offered consecutive-parallel scheme of the process. The obtained results explain the composition of impurities obtained during the production of the ${ }^{13} \mathrm{C}$-urea for diagnostic breath tests.
\end{abstract}

Key words: Propylene carbonate ammonolysis, urea preparation, two stage process, quantitative yield of product.

\section{Introduction}

Non-catalytic ammonolysis of PC (propylene carbonate) is used for obtaining urea labelled by ${ }^{13} \mathrm{C}$ isotope $[1,2]$ - the main substance for breath tests of different kind of diseases [3-5]. The process (Scheme 1 ) is conducted under ammonia pressure without use of a catalyst and solvent with high selectivity in relation to urea. In these conditions the yield of the isolated product is $98 \%$. Depending on the reaction conditions, however, small quantities of 2-hydroxypropyl urea and 2-hydroxypropyl carbamate were found except of the main by-product 1,2-propanediol (PD). Considering the medical use of the ${ }^{13} \mathrm{C}$-urea, it was interesting to find out the ways of formation of these by-products, as well as to detect other probable impurities, which will be undesirable in target urea. The purpose of this work was to determine the nature of the obtained products, depending on the conditions of propylene carbonate ammonolysis in the liquid-phase.

Corresponding author: Alexander R. Elman, head of laboratory, Ph.D., research fields: carbonylation and carboxylation reactions, catalysis, chemical technology.

\section{Experimental Section}

Propylene carbonate was loaded into steel autoclave [6] next it was sealed, and liquid ammonia was added with the use of a batcher (under own $\mathrm{NH}_{3}$ pressure of $\sim 8 \mathrm{~atm}$ ), after that the stirring and heating were turned on. During reaction, the change of pressure and temperature was monitored in the autoclave. Temperature reached the preset meaning in 20-30 minutes after the beginning of the process. After completion of gas absorption, the autoclave was cooled down to ambient temperature, excess of ammonia was dropped into the absorption system (traps with phosphoric acid), and estimated the appearance of the obtained product.

To ensure the homogeneity of test sample, the obtained product was heated with stirring up to $80{ }^{\circ} \mathrm{C}$ until obtaining of homogeneous solution and then was taken for analysis.

ESI-MS, ion trap, $m / z$ (peaks are arranged in decreasing order of intensity):

- urea $\mathrm{CON}_{2} \mathrm{H}_{4}: 61.5[\mathrm{M}+\mathrm{H}]^{+}, 83.4[\mathrm{M}+\mathrm{Na}]^{+}$, $121.5[2 \mathrm{M}+\mathrm{H}]^{+}, 143.4[2 \mathrm{M}+\mathrm{Na}]^{+}$;

- 2-hydroxypropyl carbamate $\mathrm{C}_{4} \mathrm{H}_{9} \mathrm{NO}_{3}: 142.3$ $[\mathrm{M}+\mathrm{Na}]^{+}, 261.1[2 \mathrm{M}+\mathrm{Na}]^{+}$;

- 2-hydroxypropyl urea $\mathrm{C}_{4} \mathrm{H}_{10} \mathrm{~N}_{2} \mathrm{O}_{2}: 141.5[\mathrm{M}+\mathrm{Na}]^{+}$, $259.1[2 \mathrm{M}+\mathrm{Na}]^{+}, 119.7[\mathrm{M}+\mathrm{H}]^{+}, 237.2[2 \mathrm{M}+\mathrm{H}]^{+}$; 


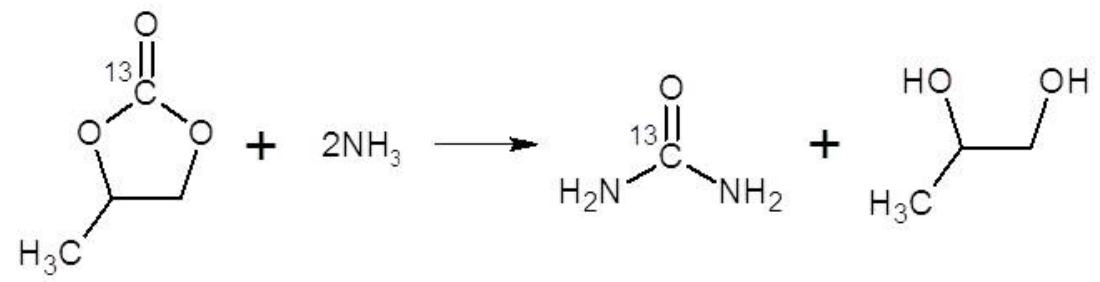

Scheme $1{ }^{13} \mathrm{C}$-Urea preparation by the ammonolysis of ${ }^{13} \mathrm{C}$-propylene carbonate.

- (2-hydroxypropyl)-carbamic acid 2-hydroxypropyl ester and carbamic acid dipropylene glycol ester $\mathrm{C}_{7} \mathrm{H}_{15} \mathrm{NO}_{4}$, which have the same molecular mass: $200.3[\mathrm{M}+\mathrm{Na}]^{+}, 377.1[2 \mathrm{M}+\mathrm{Na}]^{+}, 178.8[\mathrm{M}+\mathrm{H}]^{+}$;

- dipropylene glycol $\mathrm{C}_{6} \mathrm{H}_{14} \mathrm{O}_{3}: 157.7[\mathrm{M}+\mathrm{Na}]^{+}$.

\section{Results and Discussion}

Ammonolysis of PC was conducted on a lab apparatus described earlier [6]. Typical dependence of pressure vs. time at the reaction temperature of $126^{\circ} \mathrm{C}$ and known "technological" [1] $\mathrm{NH}_{3}$-to-PC ratio of 7:1 $(\mathrm{mol} / \mathrm{mol})$ is represented in Fig. 1.

However, in the case of more frequent registration of pressure in the reactor, the local maximum was noticed on the ascending branch of kinetic curve (Fig. 2, curve marked as $\bullet$ ). This phenomenon was discovered in many experiments: at other loading of reagents and at different temperatures. To determine nature of this feature, several experiments were carried out with various mole ratios of ammonia and PC. It turned out that with decrease of $\mathrm{NH}_{3} / \mathrm{PC}$ the first extremum becomes more and more obvious, while the second one gradually disappears; at the same time $\mathrm{P}_{\max }$ also decreased with decrease in ammonia loadings. It should be noted that at low $\mathrm{NH}_{3} / \mathrm{PC}$ values the process was completed much faster and the absorption of ammonia stopped in 1 hour (Fig. 2).

When $\mathrm{NH}_{3} / \mathrm{PC}$ ratio is big (Fig. 2, curves marked as - and $\boldsymbol{\Delta}$ ) the reaction product is white solid porous mass which consists of urea impregnated with PD; with decreasing $\mathrm{NH}_{3} / \mathrm{PC}$ the view of product obtained changes from a viscous suspension to a transparent yellowish liquid. HPLC analysis showed that at low $\mathrm{NH}_{3} / \mathrm{PC}$ values besides urea several unidentified substances are present in the end product.

HPLC/MS analysis of urea synthesis products (low $\mathrm{NH}_{3} / \mathrm{PC}$ ratio) showed the presence of the next intermediates: HPC (2-hydroxypropyl carbamate), HPU (2-hydroxypropyl urea); 2-hydroxypropyl ester of 2-hydroxypropyl carbamic acid (HPHPC), DPDC (dipropanediol carbamate), and dipropylene glycol (DPG) in small quantities. Depending on the reaction conditions HPC share in the products of the first stage was $50-70 \%$, and GLC analysis showed full conversion of the initial PC.

It should be noted that it was not possible to separate the obtained products by simple vacuum distillation, because at heating in the absence of ammonia they undergo mutual transformations, including condensation processes with the formation of dipropylene glycol and up to the formation of solid fractions.

The obtained results have allowed to assume that ammonolysis of propylene carbonate happens in two stages in the process of consumption of the double molar excess of ammonia necessary for full completion of the process.

To confirm intermediate nature of found products the reaction mass obtained on the first stage (similarly as the experiment marked as $\Delta$ on Fig. 2) was subjected to ammonolysis in the same conditions - at minimal excess of ammonia (Fig. 3). This reaction finished practically in 3 hours, and the obtained raw product looked also as a product in "standard" urea synthesis. At the same time the analysis of the obtained mass showed that the main products were urea and PD with slight quantities of HPU (4.5\%), HPC (2.2\%) and DPG (1.5\%). 


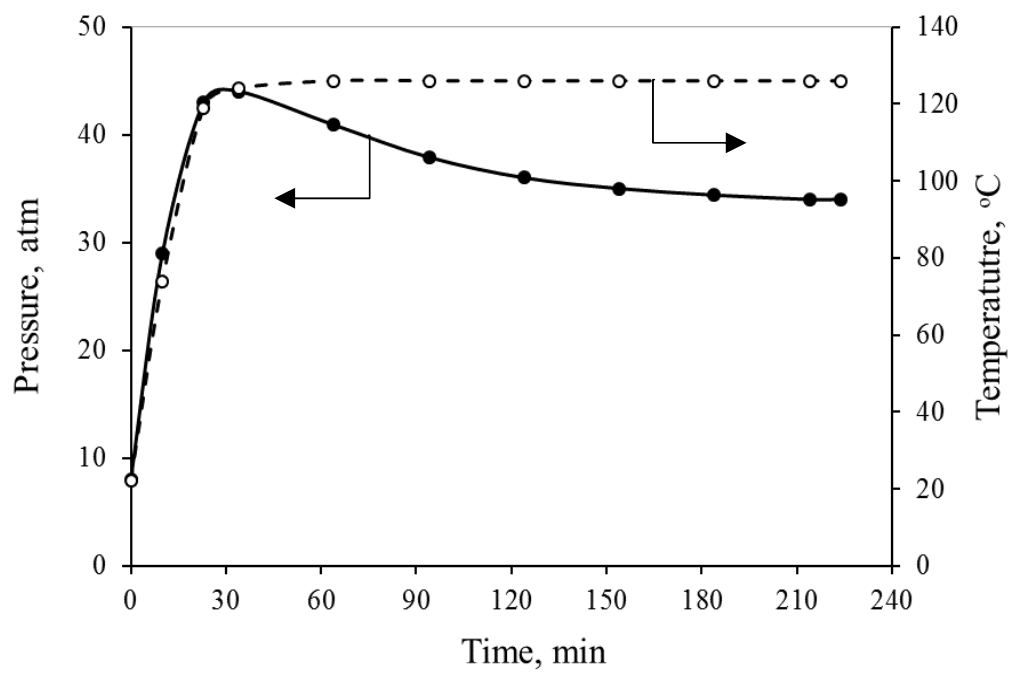

Fig. 1 Time dependences of pressure $(\bullet)$ and temperature $(\circ)$ of urea synthesis by propylene carbonate ammonolysis.

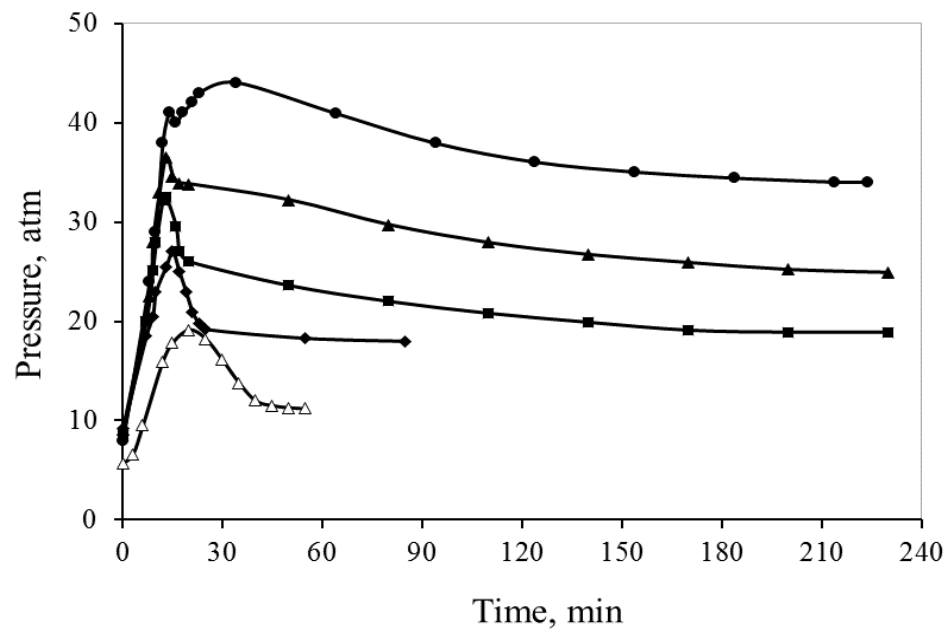

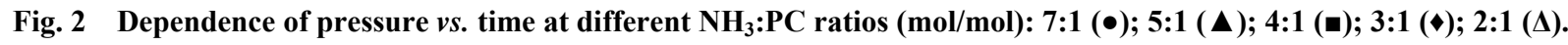

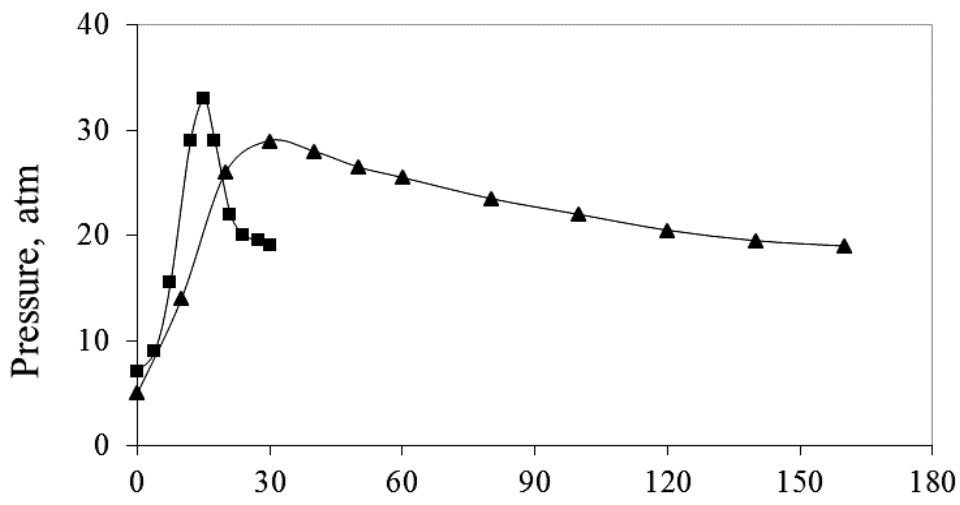

Time, min

Fig. 3 Separate carrying out 1st $(\square)$ and 2 nd $(\Delta)$ stages of ammonolysis of propylene carbonate at $126{ }^{\circ} \mathrm{C} . \mathrm{Stage} 1-\mathrm{NH}_{3}: \mathrm{PC}$ $=2: 1, \mathrm{PC}-0.6 \mathrm{~mol}$; stage $2-\mathrm{NH}_{3}: \mathrm{HPC}=2: 1\left(\mathrm{NH}_{3} / \mathrm{HPC}\right.$ ratio is calculated according to HPLC analysis of the products of stage 1). 


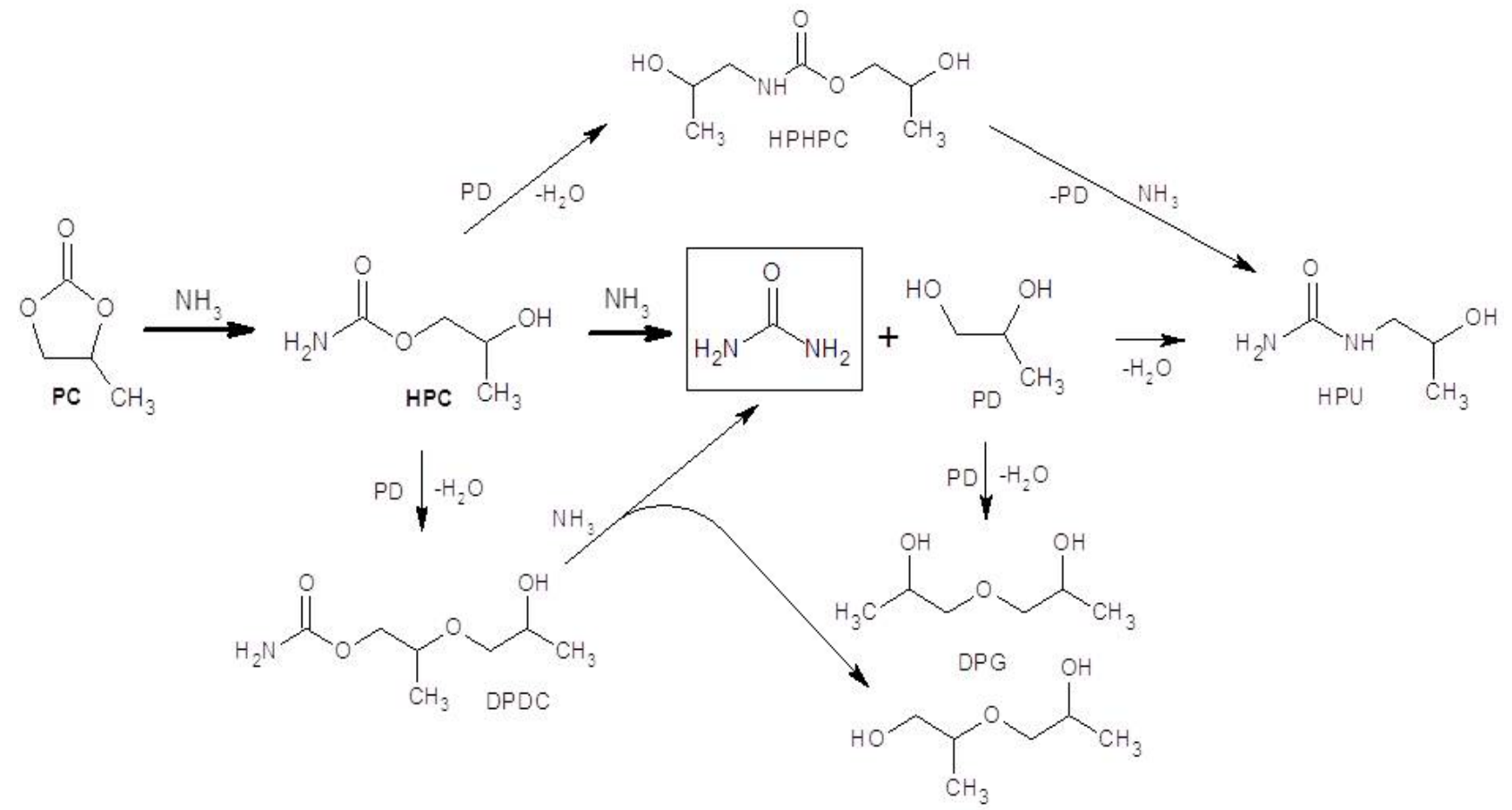

Scheme 2 Consecutive-parallel scheme of the urea formation during the ammonolysis of propylene carbonate.

Thus, it is possible to assume that urea synthesis (Scheme 1) proceeds according to the scheme 2.

The obtained results show that on the first stage (Scheme 2) the equimolar interaction of propylene carbonate with ammonia proceeds much faster than the further ammonolysis of intermediate HPC into urea; at the same time the majority of by-products form as a result of condensation reactions with participation of 1,2-propanediol.

At the same time the high selectivity to urea (see the yield of product isolated) and insignificant admixture of HPU (less than 1\%) point that the attack of ammonia on an ester group $\mathrm{C}(\mathrm{O})-\mathrm{O}$ proceeds quite easily [7] and so the ammonolysis reaction in this system is much more favorable than condensation under the action of PD, especially in the excess of ammonia. Such features of the process, despite a possibility of forming a wide range of products, allow ensuring high purity of urea using a simple purification procedure, it is very important for medical usage. At the same time, the quantitative study of each stage requires more detailed researches.

\section{Acknowledgments}

Thank State Atomic Energy Corporation "Rosatom" which provided with isotope raw materials and assisted in the realization of this work.

\section{References}

[1] Elman, A. R., Ovsyannikova, L. V., Davydov, I. E., Kushnarev, D. I., Gubanov, O. V., Zyryanov, S. M., and Sid'ko, Yu. A. 2017. Method for the production of ${ }^{13}$ C-urea. RU Patent 2,638,837, filed July 08, 2016, and issued December 18, 2017.

[2] Elman, A. R., Korneeva, G. A., Noskov, Yu. G., Khan, V. N., Shishkina, E. Yu., Negrimovskiy, V. M., Ponomarenko, E. P., Kononov. L. O., Bruk, L. G., Oshanina, I. V., Temkin, O. N., and Kuz'min, S. G. 2013. "Syntheses of Products Labeled with ${ }^{13} \mathrm{C}$ Isotope for Medicine Diagnosis." Rossiiskii Khimicheskii Zhurnal 57 (5): 3-24. (in Russian)

[3] Modak, A. S. 2007. "Stable Isotope Breath Tests in Clinical Medicine: A Review." Journal of Breath Research 1: R1-13.

[4] Schellekens, R. C, A., Olsder, G. G., Langenberg, S. M. C. H., Boer, T., Woerdenbag, H. J., Frijlink, H. W., Kosterink, J. G. W., and Stellaard F. 2009. "Proof-of-Concept Study on the Suitability of ${ }^{13} \mathrm{C}$-Urea as a Marker Substance for Assessment of in vivo Behaviour 
of Oral Colon-Targeted Dosage Forms.” British Journal of Pharmacology 158: 532-40.

[5] Cheepsattayakorn, A., and Cheepsattayakorn, R. 2013. "Breath Tests in Respiratory and Critical Care Medicine: From Research to Practice in Current Perspectives." BioMed Research International 2013: 1-20.
[6] Elman, A. R., and Smirnov, V. I. 2011. "Urea Preparation by Oxidative Carbonylation of Ammonia." Journal of Environmental Science and Engeneering 5: 1006-12.

[7] Fieser, L. F., and Fieser, M. 1970. Organicheskaya Khimia. Uglublennyi kurs. Khimia, Moscow, Vol. I, pp 445. (in Russian) 